\title{
An Improved, Computer-Based, On-Line Gamma Monitor for Plutonium Anion Exchange Process Control
}

\author{
Noah G. Pope \\ S. Fredric Marsh
}

\begin{abstract}
DISCLAIMER
This report was prepared as an account of work sponsored by an agency of the United States Government. Neither the United States Government nor any agency thereof, nor any of their employees, makes any warranty, express or implied, or assumes any legal liability or responsibility for the accuracy, completeness, or usefulness of any information, apparatus, product, or process disclosed, or represents that its use would not infringe privately owned rights. Reference herein to any specific commercial product, process, or service by trade name, trademark. manufacturer, or otherwise does not necessarily constitute or imply its endorsement, recommendation, or favoring by the United States Government or any agency thereof. The views and opinions of authors expressed herein do not necessarily state or reflect those of the United States Govermment or any agency thereof.
\end{abstract}




\title{
AN IMPROVED, COMPUTER-BASED, ON-LINE GAMMA MONITOR FOR PLUTONIUM ANION EXCHANGE PROCESS CONTROL
}

\author{
by
}

\author{
Noah G. Pope and S. Fredric Marsh
}

\begin{abstract}
An improved, low-cost, computer-based system has replaced a previously developed on-line gamma monitor. Both instruments continuously profile uranium, plutonium, and americium in the nitrate anion exchange process used to recover and purify plutonium at the Los Alamos Plutonium Facility. The latest system incorporates a personal computer that provides full-feature multichannel analyzer (MCA) capabilities by means of a single-slot, plug-in integrated circuit board. In addition to controlling all MCA functions, the computer program continuously corrects for gain shift and performs all other data processing functions. This Plutonium Recovery Operations Gamma Ray Energy Spectrometer System (PROGRESS) provides on-line process operational data essential for efficient operation. By identifying abnormal conditions in real time, it allows operators to take corrective actions promptly. The decision-making capability of the computer will be of increasing value as we implement automated process-control functions in the future.
\end{abstract}

\section{INTRODUCTION}

The major aqueous process used to recover and $\mathrm{pu}-$ rify plutonium at the Los Alamos Plutonium Facility is anion exchange in nitric acid. This process is nearly ideal for separating plutonium from a wide variety of impure materials, as the anionic nitrate complex of $\mathrm{Pu}(\mathrm{IV})$ is more strongly sorbed than any other complex ion, and few other elements show even moderate sorption from nitric acid. ${ }^{1}$

Operators at Los Alamos have traditionally followed a fixed procedure, even though feed solutions vary over a broad range of impurity compositions and concentrations. Before the earlier on-line gamma monitor $^{2}$ became available less than two years ago, process operators based most process-control decisions on only their visual observations and intuition.

Although the earlier version of the on-line gamma monitor significantly improved the efficiency of this anion exchange process, it lacked the reserve computational power and flexibility needed to support a parallel Los Alamos development effort directed toward the automation of major aqueous processes.

The objective of this work was to develop a compact, low-cost, computer-based version of the on-line gamma monitor. This improved version would provide sufficient reserve capability to compile real-time process-control data from a variety of monitors during future automated process-control applications. 
INSTRUMEN'CATION AND EQUIPMENT

Gamnaa Detector. High-purity, coaxial germanium detector of $\approx 1.80-\mathrm{keV}$ resolution and $\approx 15 \%$ ef ficiency, in a horizontal integral configuration. Canberra Industries, Meriden, Connecticut.

Bias Supply. Single-width NIM bias supply, low noise, 0 to $\pm 5 \mathrm{kV}$.

Computer. DataCAT, IBM-compatible personal computer, 512-K RAM, with dual floppy-disk drives. Datacraft, Inc., Gardena, California. Includes HARDCARD 10-megabyte fixed disk drive. Plus Development Corp., Milapitas, California.

Multichannel Analyzer. Model PCA-2000 single-slot, plug-in board with 2048-channel ADC and memory. Includes single-channel analyzer, multichannei scaler card, anà software for acquisition and display. The Nucleus, Inc., Oak Ridge, Tennessee.

Spectroscopy Amplifier. Single-width NIM spectroscopy amplifier and pile-up rejecter, model 572 . EG\&G ORTEC, Oak Ridge, Tennessee.

NIM Bin. Model 2100 bin/power supply, $150 \mathrm{~W}$. Canberra Industries, Meriden, Connecticut.

Plotter. Model 695 PC plotter, four-pen, with RS232-C serial interface. Houston Instruments, Austin, Texas.

Radioisotope Calibration Source. Barium$133,0.1-\mu \mathrm{Ci}$, sealed solid source, taped to detector to provide reference gamma energies for gain stabilization. Isotope Products Laboratories, Burbank, California.

Disk Operating System. DOS Version 2.0 or higher. IBM Corporation, Boca Raton, Florida.

Compiler. IBM Basic Compiler, Version 2.01, 1985. IBM Corporation, Boca Raton, Florida.

\section{SYSTEM INSTALLATION AND OPERATION}

Although ${ }^{239} \mathrm{Pu}$ and ${ }^{241} \mathrm{Am}$ have gamma rays that are directly suitable for passive gamma assay, the natural and depleted uranium impurities in typicai Los Alamos feed materials do not. A novel and indirect radiotracer technique therefore is used. The position of any uranium impurity that passes through the anion exchange process is traced by ${ }^{237} \mathrm{U}$, a minor alphadecay daughter of ${ }^{241} \mathrm{Pu}$ that is always present in plutonium processed at Los Alamos. This radiotracer technique is detailed in a separate report. ${ }^{2}$

A high-purity germanium gamma detector monitors the outlet stream from the anion exchange column (Fig. 1) as it flows through an existing threequarter-inch stainless steel process pipe. The detector is shielded from background radiation by a lead shield (minimum 1.5-inch thickness) that contains a lining of 0.030 -inch cadmium to absorb fluorescent $x$ rays from lead. Another cadmium absorber is inserted between the pipe and the deteictor to attenuate a major portion of the abundant 59.5-keV gamma rays from ${ }^{241} \mathrm{Am}$ (Fig. 2).

The complete on-line gamma monitor system (Fig. 3) provides real-time elution profiles of americium, uranium, and plutoniam (Fig. 4) as these elements elute from the anion exchange column. The changing detector signals refiect the varying composition of the outlet stream from the anion exchange column as (1) americium impurity elutes first, (2) uranium and other impurities elute next, and finally (3) purified plutonium elutes after being reduced from strongly sorbed $\mathrm{Pu}$ (IV) to nonsorbed $\mathrm{Pu}(\mathrm{III})$. These recorded elution profiles provide data from which operators can optimize many process parameters. The stripchart also provides a permanent record of the daily performance for each anion exchange system.

\section{COMPUTER PROGRAM SYNOPSIS}

The Plutonium Recovery Operations Gamma Ray Energy Spectrometer System (PROGRESS) program that we developed consists of nearly 1000 lines of BASIC code that controls all data acquisition, processing, and output operations. Software for the PCA multichannel analyzer plug-in card (Fig. 5), supplied by The Nucleus, Inc., must be loaded manually before the BASIC program can be executed. The PROGRESS program (see Fig. 6) then controls the vendor-supplied software. (Appendix A is a detailed description of this program.)

Many parameters and functions of the PCA-2000 plug-in card can be directly accessed from a high-level interface language. BASIC was selected for this application because it is easily programmed and is capabie of interfacing with assembly-language subroutines by 


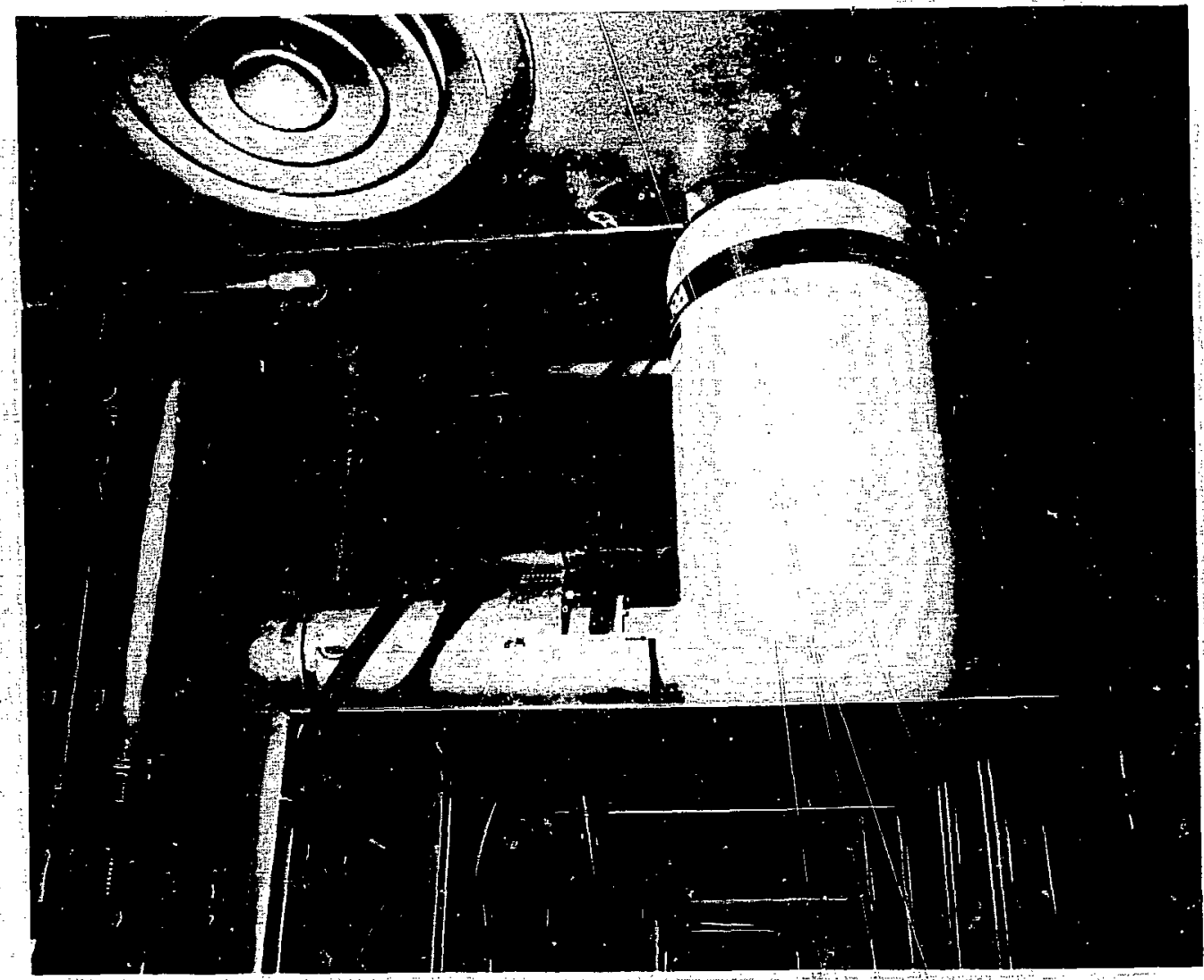

Fig. 1. High-purity germanium detector monitoring the outlet pipe from an anion exchange system at Lcs Alamos.

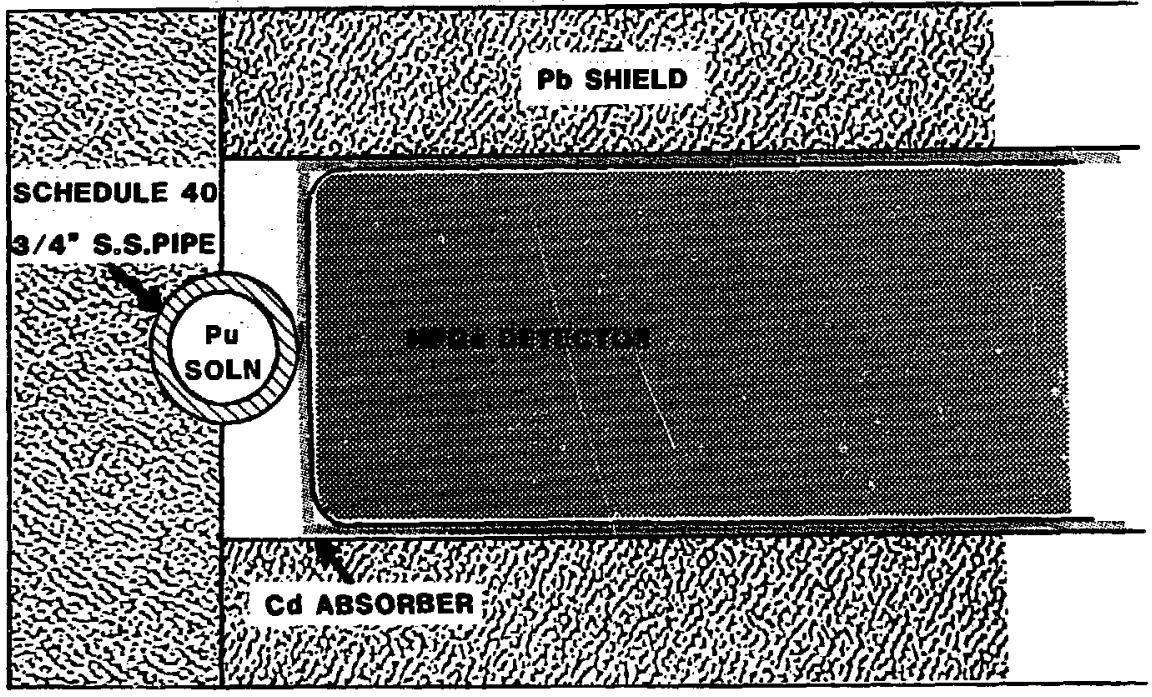

FIg. 2. Details of shielding and mounting configuration of the gamma detector. 


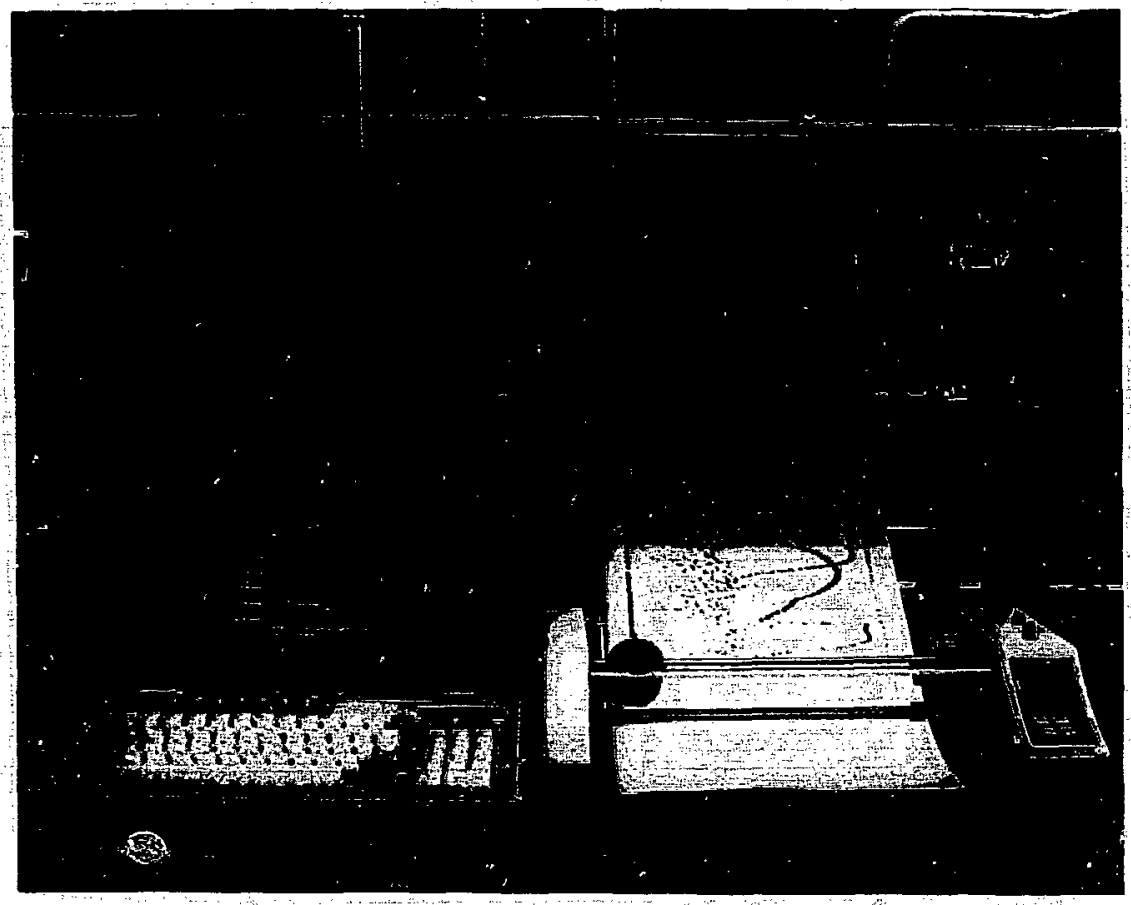

Fig. 3. Complete on-line gamma monitor system installed under glove box.

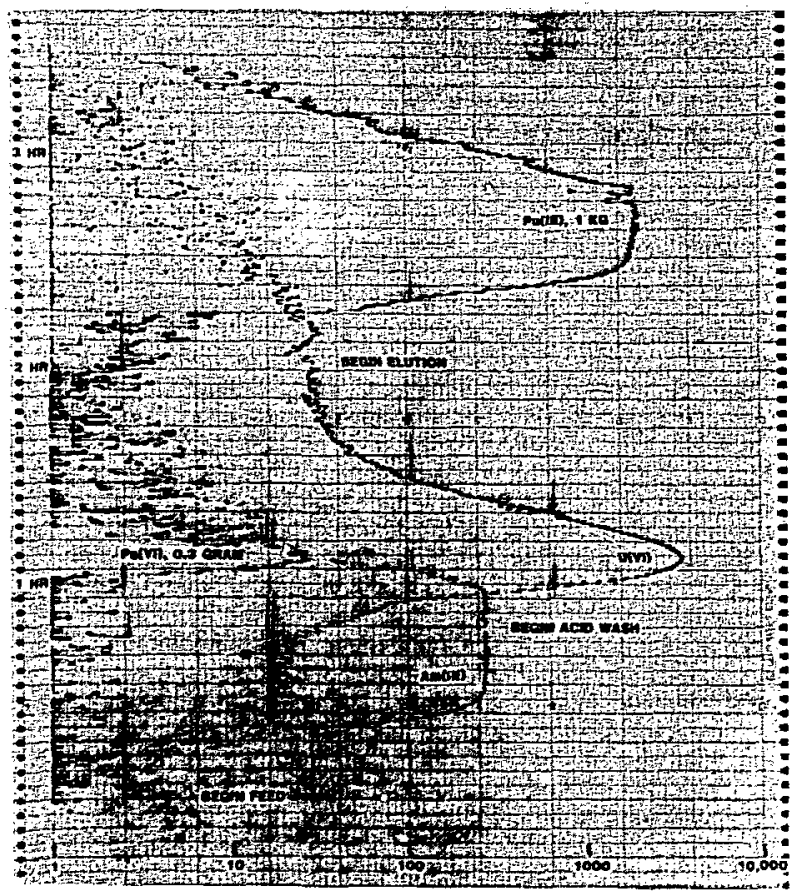

Fig. 4. Typical stripchart record from the anion exchange separation process. 


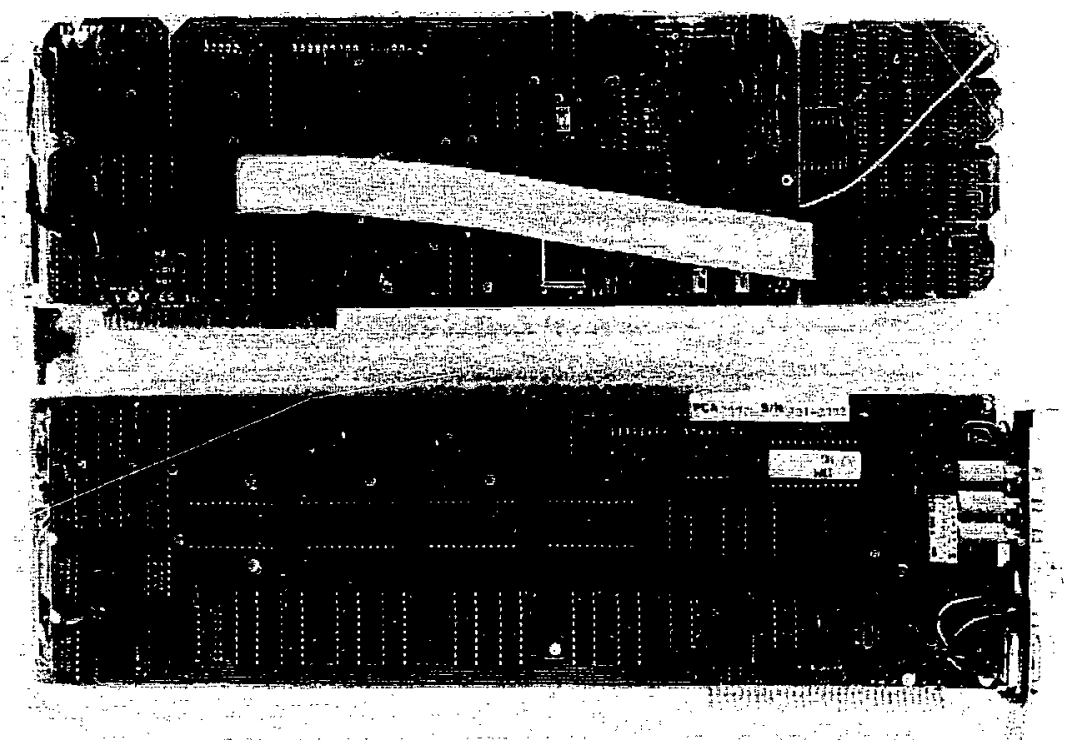

Flg. 5. The PCA-2000 single-slot, plug-in integrated circuit board that provides complete multichannel analyzer capability to a personal computer. (Only a single board is required; this photograph shows both sides of the single board.)

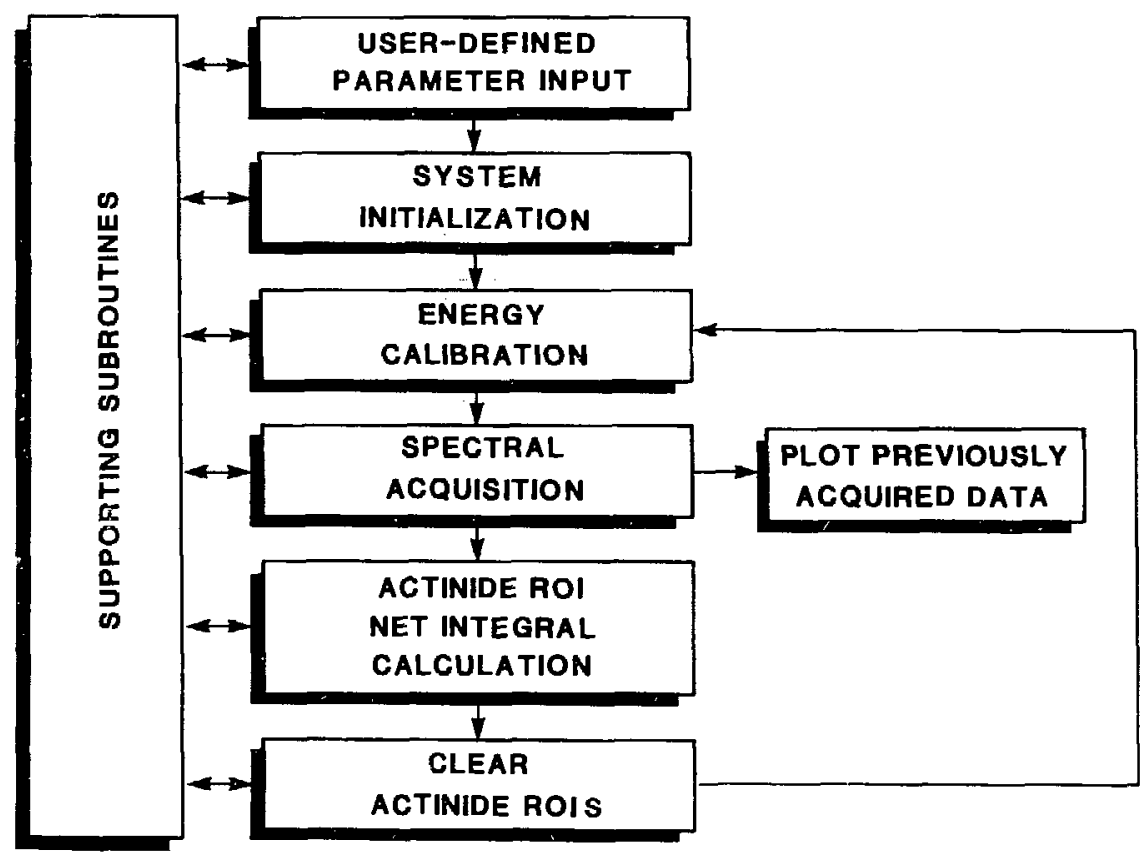

Flg. 6. Flow chart for major sections of the PROGRESS program. 
means of POKE statements and PEEK and USR functions. These cominands allow subroutines, flags, and pointers in the PCA software to be read directly into or out of memory locations on the PCA board. The detailed information required to directly access PCA software and firmware was obtained from The Nucleus, Inc. ${ }^{3,4}$

Microsoft Corporation's GW-BASIC was selected for compatibility with the DataCAT computer. (The DataCAT computer was selected because its construction and small size make it much better suited for a chemical plant environment than are competitive computers designed for office use.)

Vendor-supplied subroutines directly (1) change the cursor position, (2) update and display the spectrum, (3) calculate the region-of-interest ( $\mathrm{ROI}$ ) centroids and net integrals, (4) preset data acquisition times, and (5) start and stop data acquisition. Direct alteration of memory locations that contain logical on-and-off byte configurations accomplishes certain other operations, such as setting and clearing ROIs.

Many functions require that parameters or data be converted frow regular decimal notation to multiplebyte binary or packed binary coded decimal (BCD) format. Large portions of several subroutines therefore consist of algorithms that accomplish these conversions.

\section{PROGRAM STRATEGY}

High-purity germanium gamma detectors routinely produce high-resolution gamma peaks. Gamma spectral measurements of high-resolution peaks are most reliable when the ROI is only slightly wider than the peak being measured. Such tightly defined ROIs, however, leave the measurement system susceptible to large errors if peak positions shift during the meas urement pericd. An external electronic module typically is used to prevent gain-shift errors. Such modules automatically sense gain shift in the analog-to-digital converter (ADC) and adjust as required to correct for the detected shift. Unfortunately, the internal ADC circuitry on a PCA-2000 plug-in board is inaccessible to such external electronic gain stabilizers.

Instead, PROGRESS uses two gamma rays (one at $81 \mathrm{keV}$ and the other at $356 \mathrm{keV}$ ) from a ${ }^{133} \mathrm{Ba}$ calibration source as gamma-energy reference points for a unique software-controlled gain stabilization. PROGRESS first locates these two peaks, which nearly bracket the gamma-energy range of interest, and then determines the centroid for each. Based on the channel positions of these two calibration peaks, ROI positions are calculated and reset for ${ }^{241} \mathrm{Am}$ (59.5 keV), ${ }^{239} \mathrm{Pu}(129 \mathrm{keV})$, and ${ }^{237} \mathrm{U}(208 \mathrm{keV})$. This recalibration sequence is automatically repeated approximately every 35 seconds.

PROGRESS then initiates a spectrum acquisition loop (preset for 30 seconds in our application). Updated, cumulative spectral data are displayed on the video screen approximately every second during the acquisition period. At the end of the acquisition pericd, the program interrogates each preset ROI and calculates the net integral for each peak. These values are converted to a predetermined logarithmic scale and are output to the plotter during the subsequent data acquisition cycle.

The PROGRESS program may be executed in either an interpretive or compiled mode. The version compiled by an IBM BASIC Compiler requires approximately 35 seconds to execute a complete cycle (of which 30 seconds is data acquisition time). This is approximately 5 seconds less than the 40 seconds required to execute the interpretive version. Another compiler, IBM QuickBASIC, was rejected because it was incompatible with several essential BASIC commands.

The complete PROGRESS program (see Appendix B) includes numerous comment statements in the code. Although these statements consume a small amount of computer time in the interpretive mode, they consume no time in the compiled mode and they serve as a diagnostic aid to users who are unfamiliar with the software.

\section{ACKNOWLEDGMENTS}

The authors are grateful to Dan Blankenship of The Nucleus, Inc., for consultation concerning firmware access and programming strategy, to James Dyke for his helpful discussions and programming suggestions, and to Randy Vaughn for assistance during the installation and demonstration of the on-line monitor on a full-scale plutonium process system. 


\section{REFERENCES}

1. J. P. Faris and R. F. Buchanan, "Applications of Anion-Exchange Spectrographic Procedures in Nitric Acid Medium," U. S. Atomic Energy Commission report TID-7606, pp. 185-194 (1960).

2. S. F. Marsh and M. C. Miller, "Plutonium Process Control Using an Advanced On-Line Gamma Monitor for Uranium, Plutonium, and Americium," Los Alamos National Laboratory report LA10921 (May 1987).

3. Nucleus Personal Computer Analyzer Operating Instructions, August 1986 version, The Nucleus, Inc., Oak Ridge, Tennessee.

4. Dan Blankenship, The Nucleus, Inc., Oak Ridge, Tennessee, personal communications (1986). 


\section{APPENDIX A. DETAILED DESCRIPTION OF PROGRAM}

The PROGRESS program consists of six major sections, each of which involves supporting subroutines, as shown in Fig. 6.

\section{MAJOR PROGRAM SECTIONS}

\section{User-Defined Parameters}

Detailed below are certain essential parameters that initially must be defined by the user. These parameter definitions are retained as default settings unless they are intentionally changed.

Barium-133 Calibration Source. Gamma peaks at $81 \mathrm{keV}$ and $356 \mathrm{keV}$ from the ${ }^{133} \mathrm{Ba}$ radioisotope calibration source are used to recalibrate the system after each cycle. The program prompts the operator to define the channel numbers that bracket each of these two ROIs. These ROI settings are entered manually in the PCA-2000 mode before program execution.

Data Acquisition Time. The data acquisition time must be specified by the operator; a time of 30 seconds typically is used.

Plotter Scale. The y-axis of the plotter represents the log of the net peak area, which typically is divided into four decades that cover the range of 1 to 10,000 . The scale assigned to the $\mathrm{x}$-axis (time) is specified by the operator to allow the output to be expanded or contracted according to the estimated time required for a given process run. This time-scale control is achieved by varying the center-to-center spacing between adjacent plotted characters in increments of 0.001 inch. Default values are defined separately.

\section{System Initialization}

After the operator initializes the system using parameters selected above, the PROGRESS program controls the following cperations: (1) The blank plotter paper is scaled and advanced to the proper starting position. (2) The MCA display screen is activated to update and display the spectral data and system parameters. (3) The data acquisition time (Preset Time Function) is converted from seconds to a 3-byte binary coded decimal and executed. (4) The ROI function is set to the "ON" position.

\section{Energy Calibration}

ROIs for the two gamma peaks of the ${ }^{133} \mathrm{Ba}$ radioisotope calibration source, as defined in the PARAMETER INPUT section, are set and their centroid locations are calculated. The centroids are assigned gamma energy values of $80.998 \mathrm{keV}$ and $356.005 \mathrm{keV}$, respectively. The linear relationship between gamma energy and MCA location is calculated as $\mathrm{C}=\mathrm{mE}+\mathrm{b}$, where $\mathrm{C}$ is channel number and $E$ is energy. The slope value, $m$, is equal to the number of channels that separate the centroids of the $81-\mathrm{keV}$ and $356-\mathrm{keV}$ peaks divided by the energy that separates them. Substitution of the channel and energy values for either peak into the equation will provide the value of $b$, the zero intercept.

From this equation the peak centroid positions are calculated for gamma energies of $59.5 \mathrm{keV}, 129 \mathrm{keV}$, and $208 \mathrm{keV}$, used to monitor ${ }^{241} \mathrm{Am},{ }^{239} \mathrm{Pu}$, and ${ }^{237} \mathrm{U}$, respectively (Fig. 4). The number of channels to the left and the number of channels to the right of the peak centroid that defines the ROI for each peak are preset, based on empirical peak resolution values, which are a function of the peak energy and system resolution.

\section{Spectral Acquisition}

Previously collected data are cleared by the Clear Spectral Data function. A new acquisition cycle then is initiated by setting the START/STOP Data Acquisition function to the "ON" position. During the new data acquisition cycle, processed data from the previous acquisition and calculation cycle are output to the plotter. A print buffer in the Houston Instruments plotter allows these data to be quickly transferred without interference to the ongoing acquisition cycle.

Two alternate function-key combinations may be used during the spectral acquisition loop. The Alt and F1 keys may be simultaneously pressed to 
record the position of significant events with a special mark at the top of the plotter paper. Simultaneous depression of the Alt and F10 keys terminates the data acquisition loop and redisplays an options menu. From this options menu the operator may elect to (1) resume the measurement cycle in progress, (2) begin a new measurement cycle, or (3) exit the program and return to DOS.

If neither alternate function-key option is invoked, data acquisition continues until the Hag for data acquisition preset time registers "OFF" or timed-out status.

\section{ROI Net Integral Calculations}

The net integral of each ROI is sequentially calculated by invoking a Net Integral Calculation function within the subroutine for reading net integrals. This algorithm is repeated for each of the specified ROIs. The ROI being processed is designated by placing the MCA display cursor within that ROI.

\section{Clear ROIs}

The ROIs used to monitor ${ }^{241} \mathrm{Am},{ }^{239} \mathrm{Pu}$, and ${ }^{237} \mathrm{U}$ are cleared after each acquisition cycle is complete, in preparation for a new energy calibration. Program control then returns to the Energy Calibration algorithm at the appropriate portion of the program (Fig. 6).

\section{SUPPORTING SUBROUTINES}

\section{Set and Clear ROIs}

The vendor-supplied Set and Clear ROI function requires that each channel included in an ROI be addressed and interrogated on an individual basis. This time-consuming procedure requires approximately 0.3 second per channel, or 3 seconds for a 10-channel ROI. The more efficient subroutine developed in the PROGRESS program allows the ROI to be set and cleared by manipulating a portion of mem. ory that contains an ROI "ON/OFF" Hlag. This su' routine can set or clear a 15-channel ROI in less than 1 second.

\section{PEEK-ing}

The BASIC language PEEK function, used in conjunction with the POKE statement, allows values stored in memory locations to be read directly. This subroutine allows the program to interrogate important memory flags and pointers, such is the preset time or data acquisition flag and the RC: status flag.

\section{Using Poke Statement to Replace Value in Memory}

It can be advantageous to "trick" the PCA-2000 by replacing existing values in memory with new, more useful values. For example, the vendor-supplied function that moves the display cursor to another location must be invoked repeatedly until the desired channel location is reached. Alternatively, the value in the memory location that contains the current cursor position may be replaced with the value of the desired new cursor position. When the PCA-2000 checks for the current cursor location, it finds this new value and responds by moving the cursor to the desired position in a single operation. This subroutine can save 5 to 10 seconds of processing time per cycle.

\section{POKE-ing}

Values may be placed directly in selected memory locations using the BASIC language POKE statement. Several vendor-supplied functions are invoked by POKE-ing a function number into the appropriate memory location. These functions include Data Acquisition Start/Stop, Spectral Data Clearing, Single-Channel Cursor Movements, Centroid Calculations, and Net Integral Calculations.

\section{Centroid Calculation}

The vendor-supplied Centroid Calculation function requires that the cursor be positioned within the selected ROI. This subroutine directs the program to another subroutine that moves the cursor, as well as invokes the centroid calculation function. The calculated centroid value then is converted from packed binary coded decimal into regular decimal notation for use in subsequent calculations. 


\section{Net Integral Calculation}

The vendor-supplied Integral Calculation function is invoked and read (PEEK-ed) out of memory by this subroutine. The value then is converted from a binary number into decimal notation for subsequent manipulation. 
APPENDIX B. PROGRESS: THE COMPLETE PROGRAM

$10 \mathrm{KEY}$ OFF

20 SCREEN $0,0,0$

30 DEF SEG

40 REM

50 REM

60 REM

70 REM

80 R.EM

90 REM

100 REM

110 REM

120 REM

130 REM

140 REM

150 REM

160 REM

170 REM

180 REM

190 REM

200 REM

210 REM

220 REM

230 REM

240 REM

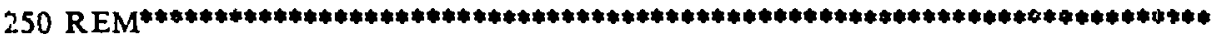

260 REM

270 REM

280 REM

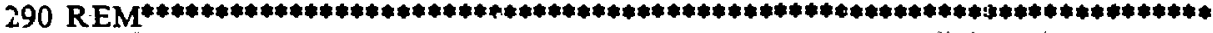

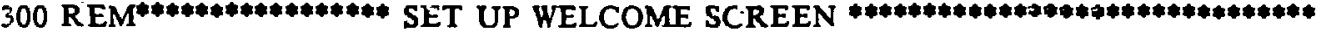

$310 \mathrm{REM} * * * * * * * * * * * * * * * * * * * * * * * * * * * * * * * * * * * * * * * * * * * * * * * * * * * * * * * * * * * * * * * * *$

320 REM

330 CLS

340 COLOR 13:LOCATE 3,23:PRINT"P":COLOR 11:LOCATE 3,24:PRINT" 1 u t o n i u m"

350 COLOR 13:LOCATE 5,23:PRINT"R":COLOR 11:LOCATE 5,24:PRINT" e c o v e r y"

360 COLOR 13:LOCATE 7,23:PRINT"O":COLOR 11:LOCATE 7,24:PRINT" p e r a $t$ i o n s

370 COLOR 13:LOCATE 9,23:PRINT"G":COLOR 11:LOCATE 9,24:PRINT" a m m a"

380 COLOR 13:LOCATE 11,23:PRINT"R ${ }^{n}$ :COLOR 11:LOCATE 11,24:PRINT" a y" $^{n}$

390 COLOR 13:LOCATE 13,23:PRINT"En:COLOR 11:LOCATE 13,24:PRINT" n e r g y

400 COLOR 13:LOCATE 15,23:PRINT"S":COLOR 11:LOCATE 15,24:PRINT ${ }^{n}$ p e c t r o s c o p y"

410 COLOR 13:LOCATE 17,23:PRINT"S":COLOR 11:LOCATE 17,24:PRINT" y s t e m"

420 COLOR 14:LOCATE 19,23:PRINT"Nuclear Materials Process Technology Group MST-12"

430 LOCATE 20,23:PRINT"Research, Development and Demonstration"

440 COLOR 18:LOCATE 22,23:PRINT ${ }^{n} E N T E R$ ACCESS CODE:"

450 LOCATE 22,40:COLOR 16:INPUT ACCESS\$

460 REM

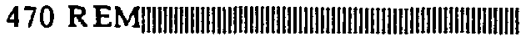

480 REM

490 REM

ACCESS IS A STRING VARIABLE THAT CAN BE CHANGED IN THIS SECTION.

500 REM

510 REM ||||||||||||||||||||||||||||||||||||||||||||||||||||||||||||||||||||| 
PROGRESS continued

\section{REM}

530 REM

540 IF ACCESS\$ $=$ "GAMMA" THEN 580

550 BEEP:BEEP

560 LOCATE 23,23:COLOR 10:PRINT"INCOR RECT- RE-ENTER CODE"

570 GOTO 440

580 REM

590 COLOR 11

600 LOCATE 23,23:PRINT"

$\therefore 10$ REM

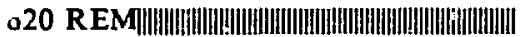

630 REM

640 REM

650 REM

BRANCH TO THE PARAMETER SETTING LOOP OR TO DEFAULT

660 REM

COLUMN MONITOR (MAIN PROGRAM BODY).

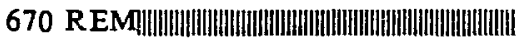

680 REM

690 LOCATE 22,23:INPUT"ENTER OPTION: (1) SET PARAMETERS Or (2) MONITOR COLUMN:",CHOOSE.OPTION\$

700 REM

710 IF CHOOSE.OPTIONS $=" 1 "$ THEN 780

720 IF CHOOSE.OPTIONS $=$ "2" THEN 1110

730 BEEP:BEEP

740 LOCATE 23,23:COLOR 10:PRINT"INCORRECT- RE-ENTER CODE"

750 GOTO 690

760 END

770 REM

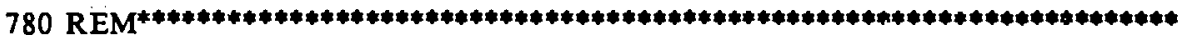

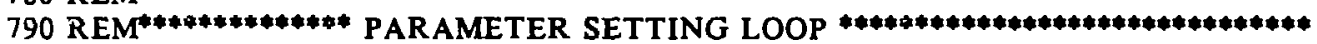

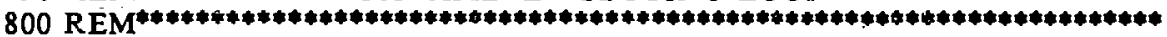

810 CLS

820 COLOR 12

830 LOCATE 3,23:PRINT"P R O G R E S S Paramet:rs"

840 COLOR 14

850 LOCATE 5,23:PRINT"Input values at the following prompts."

860 LOCATE 6,23:PRINT"(Default values are in parentheses.)"

870 COLOR 14:LOCATE 22,23:PRINT"Nuclear Materials Process Technology Group (MST-12)"

880 LOCATE 23,23:PRINT"Research, Development and Demonstration"

890 COLOR 10

900 LOCATE 8,23:INPUT"PLOTTER PAPER ADVANCE INTERVAL (6)=";ADVANCE.INTERVAL

910 IF ADVANCE.INTER VAL $=0$ THEN ADVANCE.INTERVAL $=6$

920 PAPER.ADVANCE $=12$

930 COLOR 11

940 LOCATE 10,23:INPUT"PRESET TIME IN SECONDS (30)=";PRESET.TIME

950 IF PRESET.TIME $=0$ THEN PRESET.TIME $=30$

960 COLOR 12

970 LOCATE 12,23:INPUT"1ST Ba ROI LEFT SIDE in channels (338)=";BA.1.ROISTART

980 IF BA.1.ROISTART $=0$ THEN BA.1.ROISTART $=338$

990 LOCATE 13,23:INPUT"1ST Ba ROI RIGHT SIDE in channels (356)=";BA.1.ROIEND

1000 IF BA.I.ROIEND $=0$ THEN BA.1.ROIEND $=356$

1010 COLOR 13

1020 LOCATE 15,23:INPUT"2ND Ba ROI LEFT SIDE in channels (1538)=";BA.2.ROISTART

1030 IF BA.2.ROISTART $=0$ THEN BA.2.ROISTART $=1538$

1040 LOCATE 16,23:INPUT"2ND Ba ROI RIGHT SIDE in channels (1557)=";BA.2.ROIEND 
1050 IF BA.2.ROIEND $=0$ THEN BA.2.ROIEND $=1557$

1069 COLOR 14

1070 LOCATE 18,23:INPUT"DO YOU WANT TO MAKE A CORRECTION?";CORRECTION\$

1080 IF CORRECTION\$="Y" OR CORRECTION\$=" $y^{n}$ THEN $i 70$

1090 REM

1100 GOTO 1310

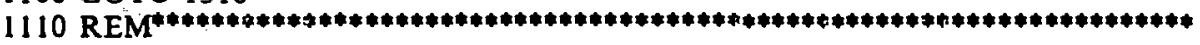

1120 REM $* * * * * * * * * * * * * * * * * * *$ DEFA ULT PAR AMETERS $* * * * * * * * * * * * * * * * * * * * * * * * *$

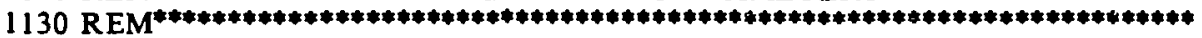

1140 REM

1150 REM THESE DEFAULT PARAMETERS ARE FOR A HOUSTON INSTRUMENTS PLOTTER 1160 REM AND FOR A SPECIFIC DETECTOR.

1170 REM

1180 ADVANCE.INTER VAL $=6$ 'DETERMINES THE SPACING BETWEEN DATA POINTS

1190 PAPER.ADVANCE $=12$

1200 PRESET.TIME $=30$

1210 BA.1.ROISTART $=338$

1220 BA.1.ROIEND $=356$

1230 BA.2.ROISTART $=1538$

1240 BA.2.ROIEND $=1557$

DETERMINES THE PLOTTER STARTING POINT

$125 \mathrm{C}$ REM

1260 REM THESE PARAMETERS SHOULD BE CHANGED AT THE SOURCE CODE LEVEL

1270 REM IF THIS PROGRAM IS TO BE USED ON A NEW SYSTEM.

1280 REM

$1290 \mathrm{REM} * * * * * * * * * * * * * * * * * * * * * * * * * * * * * * t * * * * * * * * * * * * * * * * * * * * * * * * * * 4 * * * * * * * * * * *$

1300 REM

1310 REM

1320 LPRINT ";: V3 AD P1 8,0,8,1900 U "

1330 LPRINT "; 8,440 D 0,440 U 0,880 D 8,880 U 8,1319 D 0,13,9 U 0,1759 D 8,1759 U*

1340 REM

1350 ADVANCE =PAPER.ADVANCE

1360 REM

1370 REM

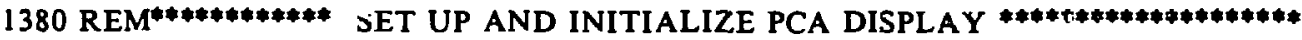

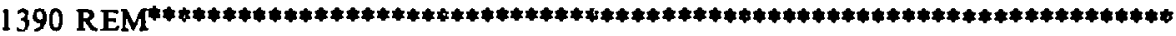

1400 REM

1410 CLS

1420 REM

1430 SCREEN 2 ' HIGH RESOLUTION GRAPHICS MODE

$1440 \mathrm{~F}=2$

1450 GOSUB 6430

$1460 \mathrm{~F}=3$

1470 GOSUB 6430

$1480 \mathrm{~F}=4$

1490 GOSUB 6430

- DISPLAY INITIALIZATION

- GOTO POKING SUBROUTINE

- PARAMETERS UPDATE

- GOTO POKING SUBROUTINE

- SPECTRUM UPDATE

' GOTO POKING SUBROUTINE

1500 REM

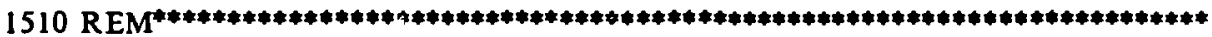

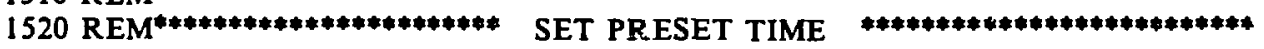

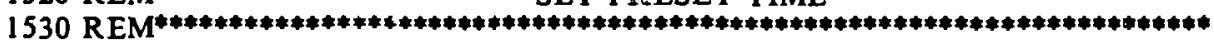

1540 REM

1550 REM

1560 REM

1570 REM

1580 REM

PRESET TIME WILL BE 30 SECONDS.

THE ACQUISITION PRESET TIME FUNCTION IS A

3-BYTE PACKED BINARY CODED DECIMAL 
1590 REM

1600 PT=PRESET.TIME

1610 REM

1620 PT $1=\operatorname{INT}(\mathrm{PT} / 10000)$

- BCD NUMBER FOR ONES AND TENS

1630 PT2=INT $((P T-P T 1 * 10000) / 100)$ ' BCD NUMBER FOR HUNDREDS \& THOUSANDS

1640 PT3 $=$ INT(PT-FT I*10000-PT2*100) ' BCD \# FOR 10 THOUSANDS AND $1001000^{\prime} S$

1650 REM

1660 REM

1670 REM

CONVERT DECIMAL VALUES TO HEX.

1680 REM

1690 PT $1=$ INT(PT $1 / 10)^{*} 16+\operatorname{INT}\left(\mathrm{PT} 1-\left(\operatorname{INT}(\mathrm{PT} 1 / 10)^{*} 16\right)^{*}(10 / 16)\right)$

1700 PT2 $=$ INT(PT2 $/ 10)^{*} 16+$ INT(PT2-(INT(PT2/10)* 16$\left.)^{*}(10 / 16)\right)$

1710 PT3=INT(PT3/10)* $16+$ INT(PT3-(INT(PT3/10)* 16$) *(10 / 16)$ )

1720 REM

1730 BYTE $1=$ PT 3

1740 . BYTE $2=P T 2$

' ASSIGN VARIABLES TO PACK BCD NUMBERS

1750 BYTE3=PT 1

1760 REM

$1770 \mathrm{~F}=141$

1780 REM

1790 GOSUB 6140

1800 REM

$1810 \quad F=25$

1820 REM

1830 REM

1840 GOSUB 6430

- ACQUISITION PRESET TIME FUNCTION NUMBER

- GOTO SUBROUTINE TO REPLACE VALUE IN MEMORY

1850 REM

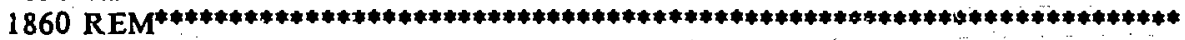

1870 REM R $^{* * * * * * * * * * * * * *}$ END PRESET TIME SETTING *************************

$1880 \mathrm{REM} * * * * * * * * * * * * * * * * * * * * * * * * * * * * * * * * * * * * * * * * * * * * * * * * * * * * * * * * * * * * * * * * * *$

$1890 \quad F=158$

1900 GOSUB 5900

1910 PRINT VALUE0,VALUE1,TOTAL

1920 IF VALUE $0=1$ THEN 1970

$1930 \mathrm{~F}=39$

1940 GOSUB 6520

1950 GOTO 1890

1960 REM

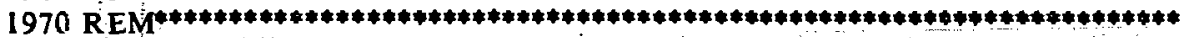

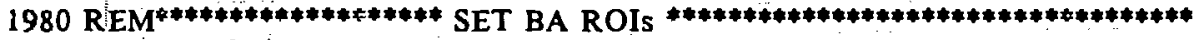

1990 REM

2000 REM

2010 REM

2020 REM

2030 REM

2040 REM

2050 REM

2060 REM

2070 REM

2080 REM

2090 REM

2100 REM

BA.1.ROISTART, BA.1.ROIEND, BA.2.ROISTART, AND BA.2.ROIEND

ARE DEFINED IN THE PARAMETERS LOOP OR IN THE DEFAULT SECTION.

THE REST OF THE ROI SETTINGS ARE DEPENDENT ON THESE TWO ROIS.

THEY SHOULD BRACKET THE Ba-133 81-KeV AND 356-KeV PEAKS.

THE ENERGY CALIBRATION PERFORMED WITH THESE PEAKS

2110 REM

IS USED TO CALCULATE THE CHANNEL \# FOR THE REMAINING ROIs.

2120 REM 


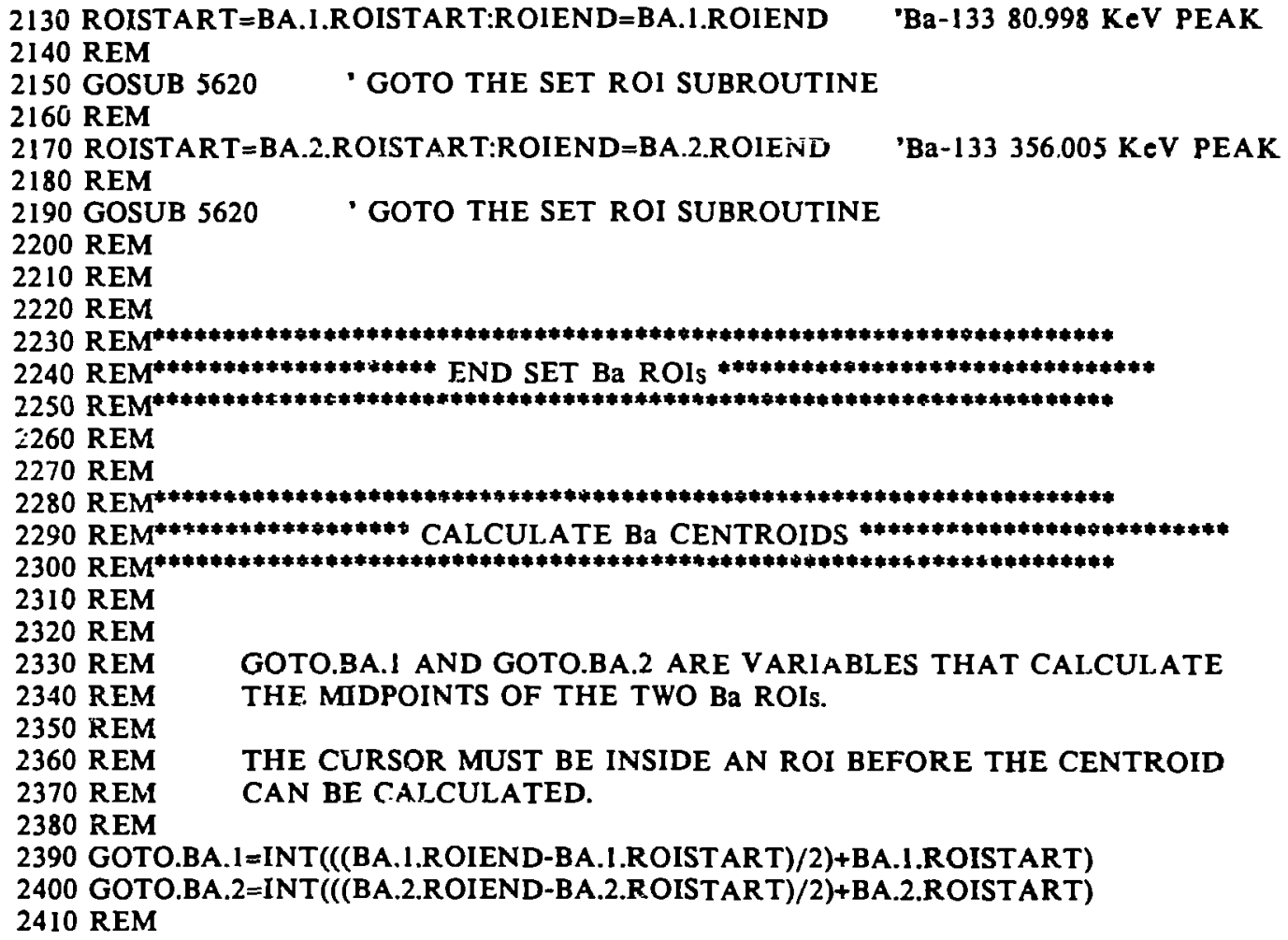


2660 BACENT $2=C$ 2670 REM 2680 REM 2690 DELTAENERGY $=275.017$ 2700 REM 2710 DELTACHANNEL=BACENT2-BACENT 1 'DIFF IN CHANNELS BETWEEN TWO CENTROIDS 2720 REM 273 ก REM

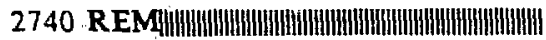
2750 REM 2760 REM 2770 REM 2780 REM 2790 REM 2800 REM 28.10 REM 2820 REM 2830 REM 2840 REM 2850 REM 2860 REM 2870 REM 2880 REM 2890 REM 2900 REM 2910 REM 2920 SLOPE=DELTACHANNEL ${ }^{\prime}$ DELT AENERGY 2930 REM 2940 REM 2950 REM 2960 YINTERCEPT $=$ BACENT2-(SLOPE*356.005) 2970 REM 2980 REM 2990 REM 3000 AMSTR $=$ INT(SLOPE* $56.784+$ Y INTERCEPT) 3010 AMEND $=$ INT(SLOPE*61.084+YINTERCEPT) 3020 REM

3030 PUSTR=INT(SLOPE*127.447+YINTERCEPT) 3040 PUEND=INT(SLOPE* $130.887+$ YINTERCEPT) 3050 REM 3060 USTR=INT(SLOPE*205.505+YINTERCEPT) 3070 UEND=INT(SLOPE*209.591+YINTERCEPT) 3080 REM 3090 PU2STR=INT(SLOPE*410.796+YINTERCEPT) 3100 PU2END=INT(SLOPE*415.798+YINTERCEPT) 3110 REM 3120 REM 3130 REM* $^{*}$ 3140 REM 3150 REM ${ }^{* * * * * * * * * * * * * * * * * *}$ SET REGIONS OF INTEREST $* * * * * * * * * * * * * * * * * * * *$ PARAMETERS

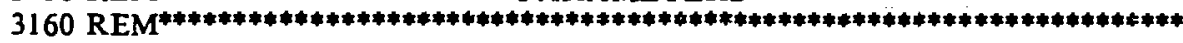
3170 REM 3180 REM 3190 REM
- LEFT SIDE OF Am ROI

' RIGHT SIDE OF Am ROI

- LEFT SIDE OF 1st Pu ROI

- RIGHT SIDE OF Ist Pu ROI

- LEFT SIDE U ROI

' RIGHT SIDE OF U ROI

- LEFT SIDE OF 2nd Pu ROI

- RIGHT SIDE OF 2nd PU ROI
SET FIRST ROI ABOUT Am-241 59.5-KeV PEAK. 
PROGRESS continued

3200 REM

3210 ROIST $A$ RT=AMSTR:ROIEND=AMEND

3220 REM

3230 GOSUB 5620

' GOTO THE SET ROI SUBROUTINE

3240 REM

3250 REM

3260 REM

SET SECOND ROI ABOUT Pu-239 129.3-KeV PEAK.

3270 REM

3280 ROISTART $=$ PUSTR:ROIEND=PUEND

3290 REM

3300 GOSUB 5620

' GOTO THE SET ROI SUBROUTINE

3310 REM

3320 REM

3330 REM

SET THIRD ROI ABOUT U-237 208-KeV PEAK.

3340 REM

3350 ROISTART=USTR:ROIEND=UEND

3360 REM

3370 GOSUB 5620

3380 REM

3390 REM

3400 REM

3410 REM

' GOTO THE SET ROI SUBROUTINE

3420 'ROISTART=PU2STR:ROIEND=PU2END

3430 REM

3440 'GOSUB 37700 ' GOTO THE SET ROI SUBROUTINE

3450 REM

3460 REM

3470 REM $\mathrm{R}^{* * * * * * * * * * * * * * * * * * * * * * * * * * * * * * * * * * * * * * * * * * * * * * * * * * * * * * * * * * * * * * * *}$

3480 REM $M^{* * * * * * * * * * * * * * * * *}$ END SET ROI PARAMETERS $* * * * * * * * * * * * * * * * * * * * * 3$

$3490 \mathrm{REM} \mathrm{R}^{* * * * * * * * * * * * * * * * * * * * * * * * * * * * * * * * * * * * * * * * * * * * * * * * * * * * * * * * * * * * * * * * * * * *}$

3500 REM

3510 REM

$3520 \mathrm{REM} * * * ;+* * * * * * * * * * * * * * * * * * * * * * * * * * * * * * * * * * * * * * * * * * * * * * * * * * * * * * * * * * * * * * *$

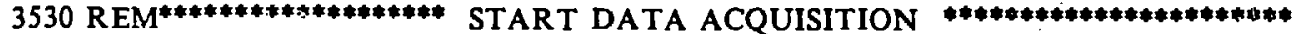

$3540 \mathrm{REM}^{* * * * * * * * * * * * * * * * t * * * * * * * * * * * * * * * * * * * * * * * * * * * * * * * * * * * * * * * * * * * * * * * * *}$

3550 REM

3560 REM

$3570 \mathrm{~F}=6$

3580 REM

3590 GOSUB 6540

' ERASE SPECTRAL DATA

3600 REM

3610 REM

3620 BEEP

3630 REM

$3640 \mathrm{~F}=5$

3650 REM

3660 GOSUB 6430

- DATA ACQUISITION START/STOP

3670 REM

3680 REM

3690 KEM $* * * * * * * * * * * * * * * * * * * * * * * * * * * * * * * * * * * * * * * * * * * * * * * * * * * * * * * * * * * * * * * * *$

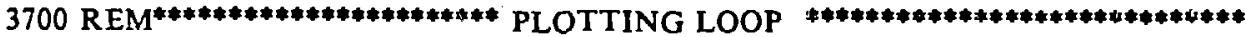

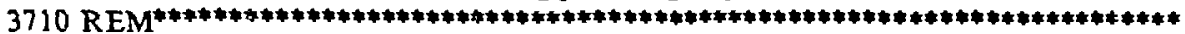

3720 DEF SEG

3730 ADVANCE=ADVANCE+ADVANCE.INTER VAL 
PROGRESS continued

3740 IF AM241=0 THEN AM241=1

3750 IF PU2 $41=0$ THEN PU24 $1=1$

3760 IF U237 $=0$ THEN U237 $=1$

3770 AM241 ADJ $=$ INT(LOG(AM241/PRESET.TIME)*200)

3780 PU241 ADJ=INT(LOG(PU241/PRESET.TIME)*200)

3790 U237ADJ=INT(LOG(U237/PRESET.TIME)*200)

3800 IF AM241 ADJ $<1$ THEN AM241 ADJ=1

3810 IF PU241ADJ $<1$ THEN PU241ADJ $=1$

3820 IF U237ADJ $<1$ THEN U237ADJ $=1$

$3830 \mathrm{REM} \mathrm{R}^{* * * * * * * * * * * * * * * * * * * * * * * * * * * * * * * * * * * * * * * * * * * * * * * * * * * * * * * * * * * * * * * * * *}$

3840 REM

HOUSTON INSTRUMENTS MODEL \#695 PLOTTER SUBROUTINE

3850 REM

3860 LPRINT ": A P1"+STR\$(ADVANCE)+","+STR\$(AM241ADJ)+"S12 A "

3870 LPRINT ":: A P2"+STRS(ADVANCE)+","+STRS(PU241 ADJ)+"S12 P "

3880 LPRINT ": A P3"+STR\$(ADVANCE)+","+STR (U237ADJ)+"S12 U "

3890 IF TRIGGER=1 THEN LPRINT ";: A P3"+STRS(ADVANCE)+",18 $\overline{85}+$ +S12 L"

3900 LPRINT ";: "+STRS(ADVANCE+1000)+","+STRS(U237ADJ)

3910 REM

3920 TRIGGER $=0$

3930 REM

3940 REM

3950 REM

3960 REM

$3970 \mathrm{~F}=3$

3980 REM

3990 GOSUB 6430 ' GOTO POKING SUBROUTINE

4000 REM

4010 INTERUPTS=INKEYS

4020 REM

4030 IF INTERUPT $\$=C H R \$(0)+C H R \$(113)$ THEN $3390 \quad$ 'GOTO MENU

4040. REM

4050 IF INTERUPT $\$=C H R \$(0)+C H R \$(104)$ THEN TRIGGER $=1$

4060 REM

4070 IF TRIGGER=1 THEN SOUND 4000,2

4080 REM

4090 REM

4100 REM

$4110 \mathrm{~F}=4$

4120 REM

4130 GOSUB 6430 ' GOTC POKING SUBROUTINE

4140 REM

4150 REM

4160 REM

$4170 \mathrm{~F}=140$

4180 REM

419] GOSUB 5910 ' GOTO PEEKING SUBROUTINE

4200 REM

4210 IF VALUE0 $=0$ THEN 3970 'A VALUE OF "O" MEANS SYSTEM IS ACQUIRING DATA

4220 REM

4230 CLS

4240 REM

4250 REM

$4260 \mathrm{REM}^{* * * * * * * * * * * * * * * * * * * * * * * * * * * * * * * * * * * * * * * * * * * * * * * * * * * * * * * * * * * * * * * * * * * *}$

4270 REM*

END DATA ACQUISITION 


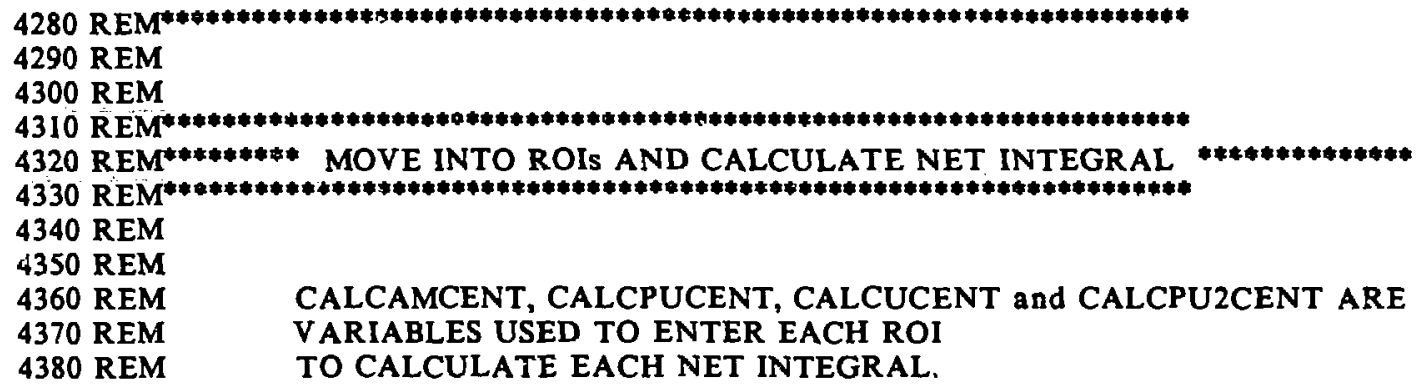




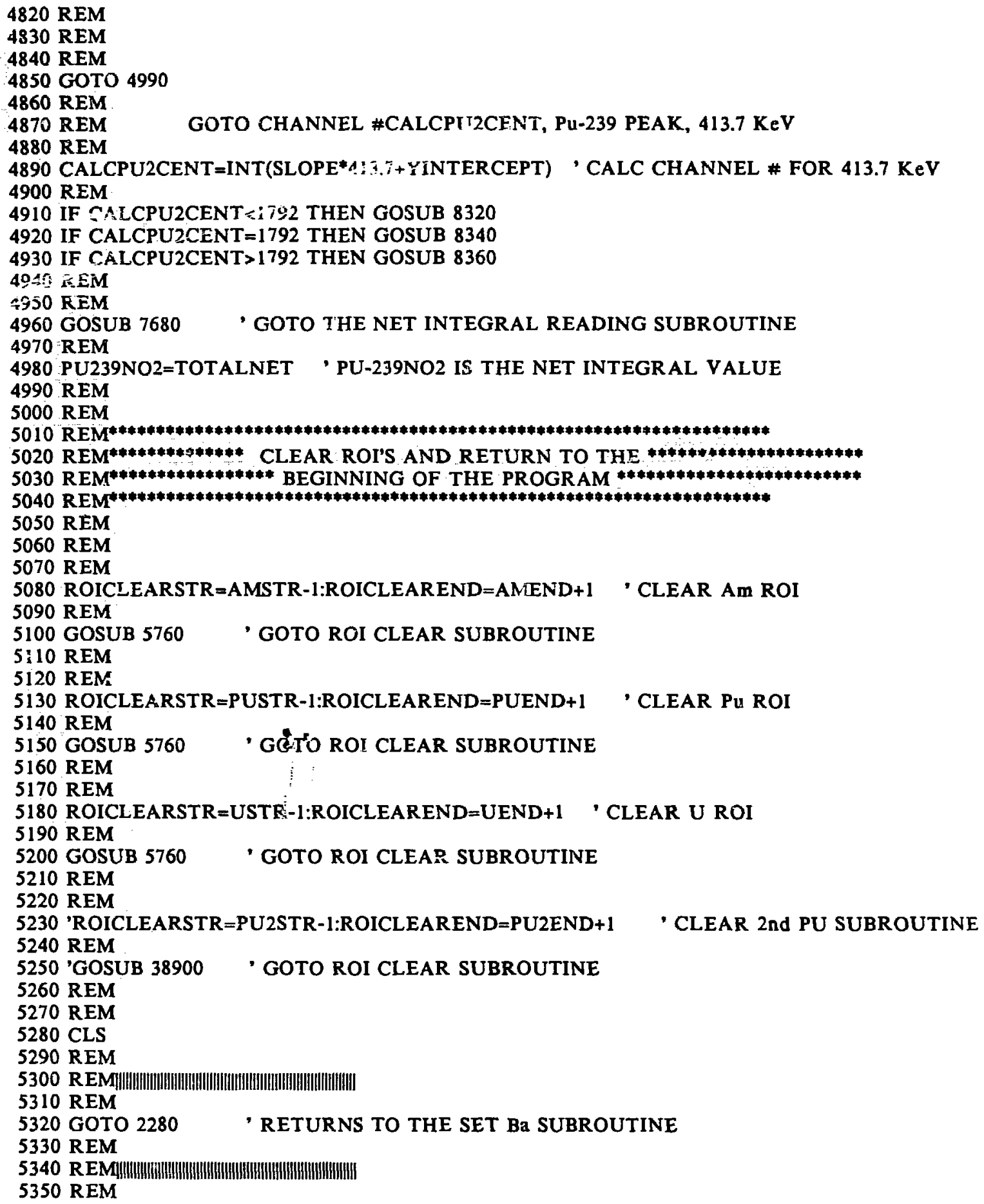


PROGRESS continued

5360 REM

5370 REM

5380 REM

5390 REM

5400 REM

5410 REM

END MAIN BODY OF PROGRAM

5420 REM END MAIN BODY OF PROGRAM

5430 REM END MAIN BODY OF PROGRAM

5440 REM

5450 REM

5460 REM

5470 REM

5480 REM

5490 REM

5500 REM

5510 REM

5520 REM

5530 REM

5540 REM

5550 REM

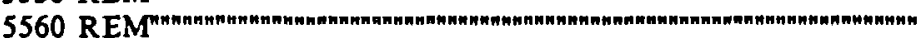

5570 REM

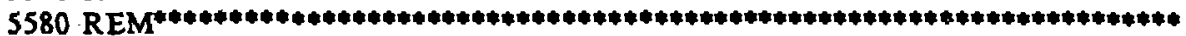

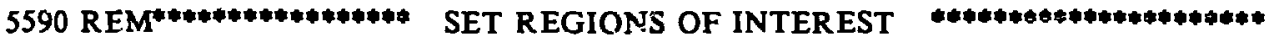

$5600 \mathrm{REM}^{* *+* * * * * * * * * * * * *}$ SUBROUTINE

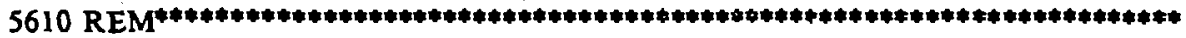

3620 DEF SEG $=\& H E 000$

5630 FOR I=ROISTART TO ROIEND

5640 ROI=PEEK $(I * 4+3)$

5650 IF ROI $>127$ THEN 5680

5660 ROI $=\mathrm{ROI}+128$

5670 POKE $\left(I^{*} 4+3\right)$, ROI

5680 NEXT I

$5690 \mathrm{REM} * * * * * * * * * * * * * * * * * * * * * * * * * * * * * * * * * * * * * * * * * * * * * * * * * * * * * * * * * * * * * * * * * * * *$

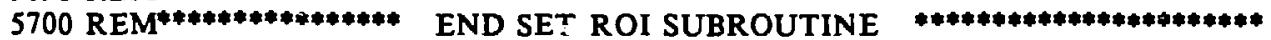

$5710 \mathrm{REM} * * * * * * * * * * * * * * * * * * * * * * * * * * * * * * * * * * * * * * * * * * * * * * * * * * * * * * * * * * * * *$

5720 RETURN

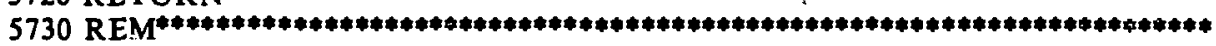

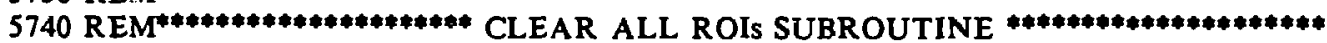

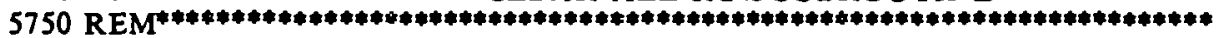

5760 REM

5770 DEF SEG $=\& H E 000$

5780 FOR ROICLEAR=ROICLEARSTR TO ROICLEAREND

5790 ROI $=$ PEEK(ROICLEAR* $4+3$ )

5800 IF ROI $<128$ THEN 5830

5810 ROI=ROI- 128

5820 POKE(ROICLEAR *4+3),ROI

5830 NEXT ROICLEAR

5840 REM

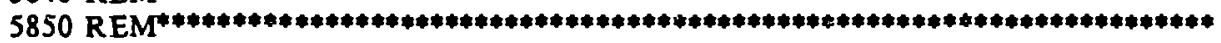

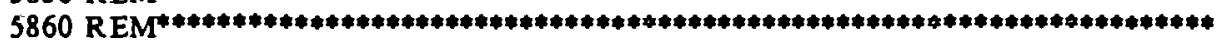

5870 RETURN

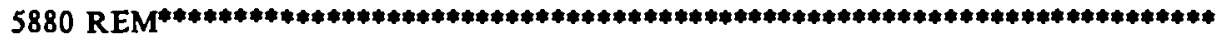

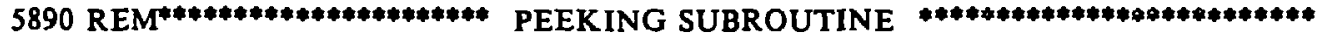




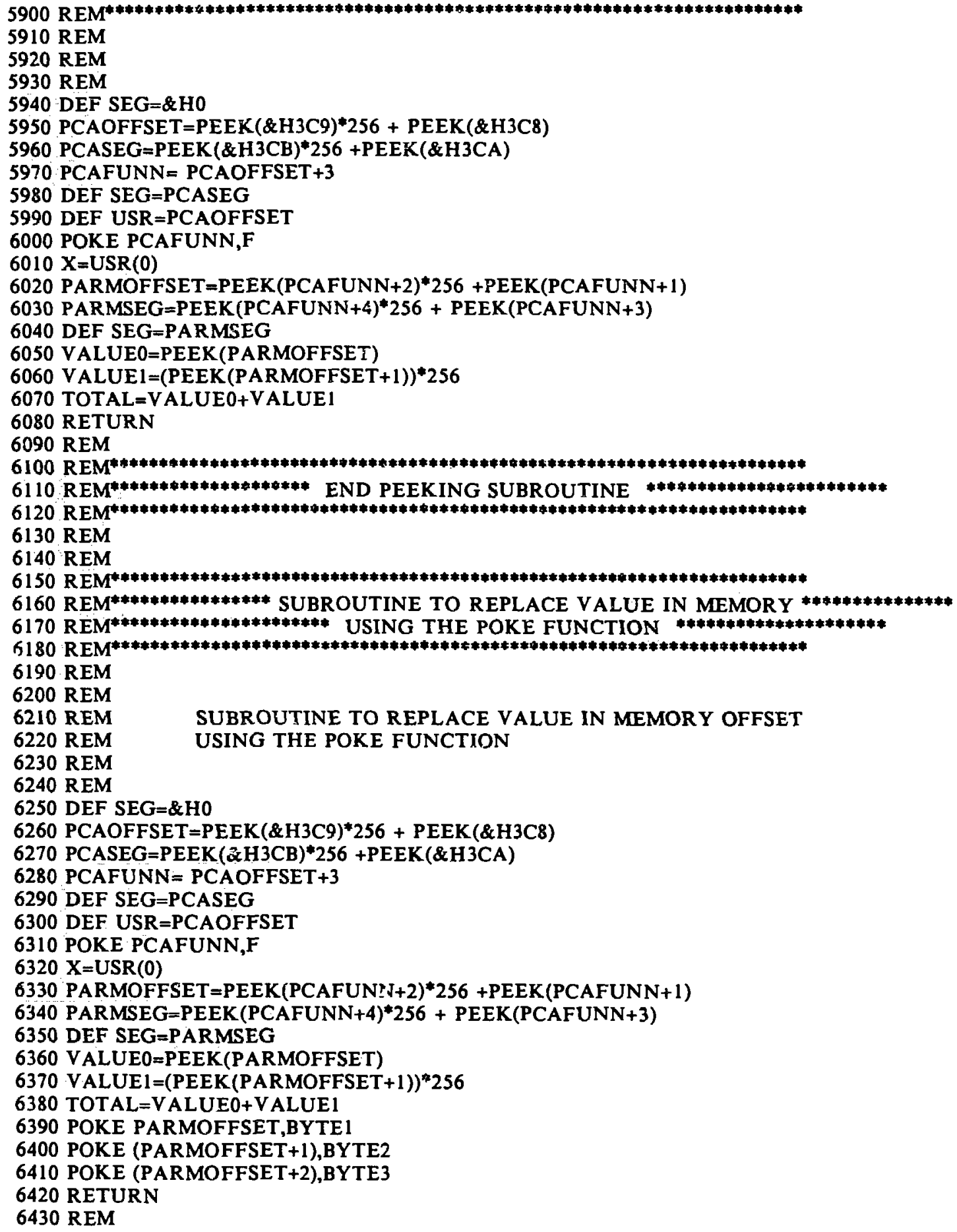




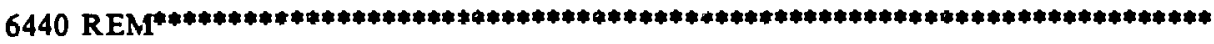

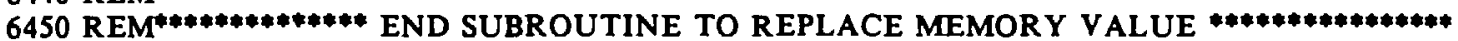

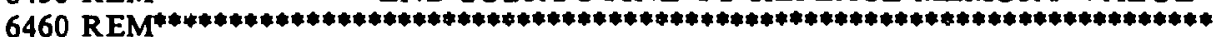
6470 REM 6480 REM 6490 REM

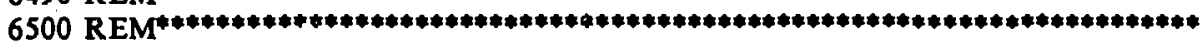

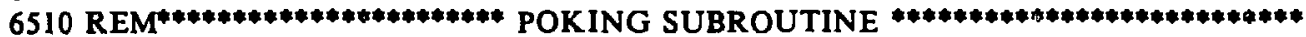

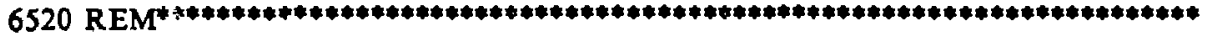

6530 REM

6540 REM

6550 DEF SEG $=\& H 0$

6560 PCAOFFSET $=$ PEEK $(\& H 3 C 9) * 256+\operatorname{PEEK}(\& H 3 C 8)$

6570 PCASEG $=$ PEEK $(\& H 3 C B) * 256+$ PEEK(\&H3CA)

6580 PCAFUNN $=$ PCAOFFSET +3

6590 DEF SEG=PCASEG

6600 DEF USR =PCAOFFSET

6610 POKE PCAFUNN,F

$6620 \mathrm{X}=\mathrm{USR}(0)$

6630 RETURN

6640 REM

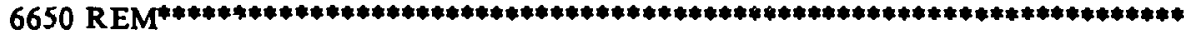

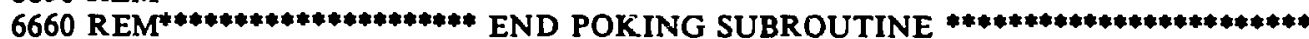

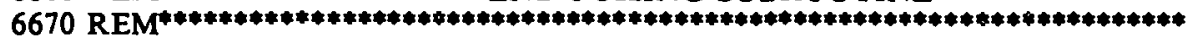

6680 REM

6690 REM

6700 REM

6710 REM

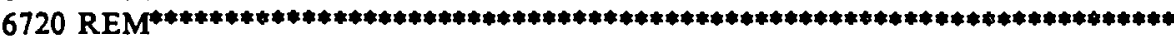

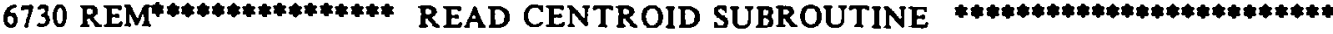

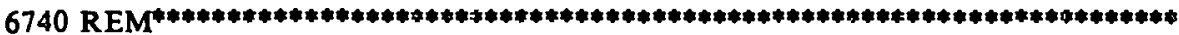

6750 REM

6760 REM

6770 DEF SEG

$6780 \mathrm{~F}=155$

6790 GOSUB 6140

$6800 \mathrm{~F}=34$

6810 GOSUB 6430

$6820 \mathrm{~F}=15$

6830 GOSUB 6550

6840 REM

$6850 \mathrm{~F}=169$

6860 DEF SEG $=\& H 0$

6870 PCAOFFSET $=$ PEEK(\&H3C9)*256 + PEEK(\&H3C8)

6880 PCASEG $=$ PEEK $(\& H 3 C B) * 256+$ PEEK(\&H3CA)

6890 PCAFUNN $=$ PCAOFFSET +3

6900 DEF SEG $=$ PCASEG

6910 DEF USR=PCAOFFSET

6920 POKE PCAFUNN,F

$6930 \mathrm{X}=\mathrm{USR}(0)$

6940 PARMOFFSET=PEEK(PCAFUNN+2)*256 +PEEK(PCAFUNN+1)

6950 PARMSEG=PEEK(PCAFUNN+4)*256 + PEEK(PCAFUNN+3)

6960 DEF SEG-PARMSEG

6970 A=PARMOFFSET 
PROGRESS continued

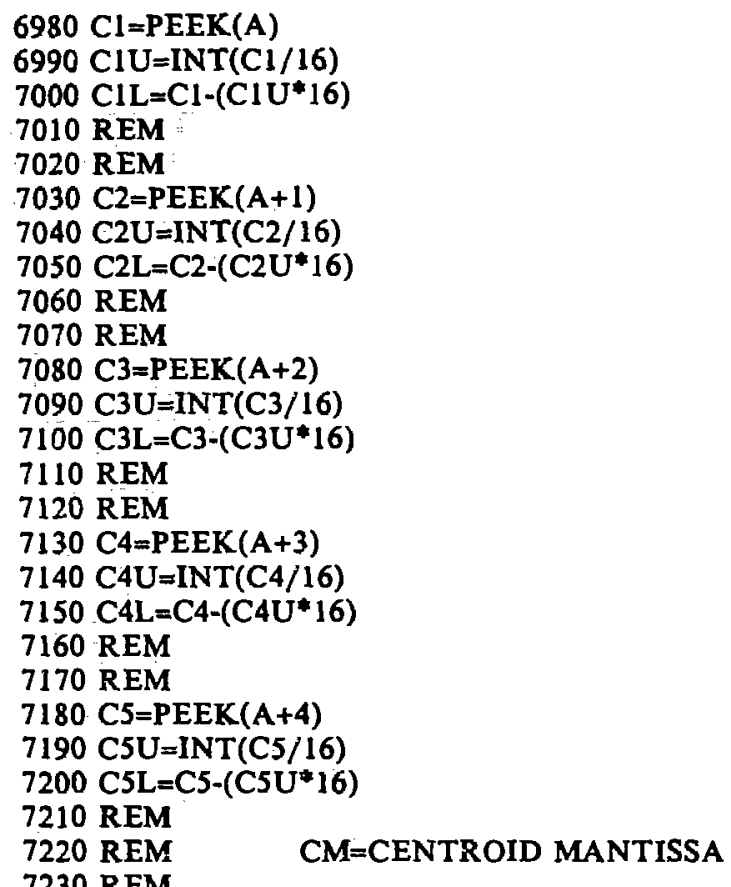

7230 REM

$7240 \mathrm{CM}=\mathrm{C} 1 \mathrm{~L}+\mathrm{C} 1 \mathrm{U}^{*} 10+\mathrm{C} 2 \mathrm{~L} * 100+\mathrm{C} 2 \mathrm{U} * 1000+\mathrm{C} 3 \mathrm{~L} * 10000+\mathrm{C} 3 \mathrm{U}^{*} 100000 !+\mathrm{C} 4 \mathrm{~L} * 1000000 !+\mathrm{C} 4 \mathrm{U}^{*} 1 \mathrm{E}+07+\mathrm{C} 5 \mathrm{~L} * 10000$ $0000 \#$

7250 REM

7260 REM CE=CENTROID EXPONENT

7270 CE $=$ PEEK $(A+5)$

$7280 \mathrm{C}=\mathrm{CM} /\left(10^{\wedge}(9-\mathrm{CE})\right)$

7290 RETURN

T300 REM

$7310 \mathrm{REM} * * * * * * * * * * * * * * * * * * * * * * * * * * * * * * * * * * * * * * * * * * * * * * * * * * * * * * * * * *$

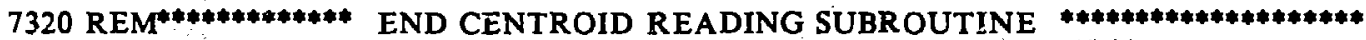

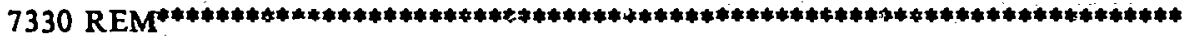

7340 REM

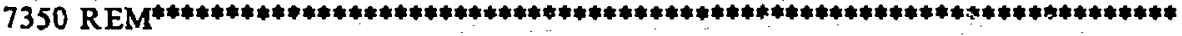

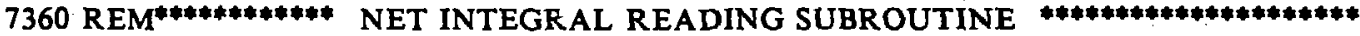

$7370 \mathrm{REM}^{* * * * * * * * * * * * * * * * * * * * * * * * * * * * * * 4 * * * * * * * * * * * * * * * * * * * * * * * * * * * * * * * * * * * * *}$

7380 REM

$7390 \mathrm{~F}=15$

7400 GOSUB 6530

7410 DEF SEG $=\& H 0$

7420 PCAOFFSET $=$ PEEK $(\& H 3 C 9) * 256+\operatorname{PEEK}(\& H 3 C 8)$

7430 PCASEG $=$ PEEK $(\& H 3 C B) * 256+$ PEEK $(\& H 3 C A)$

7440 PCAFUNN $=$ PCAOFFSET +3

7450 DEF SEG $=$ PCASEG

7460 DEF USR $=$ PCAOFFSET

7470 POKE PCAFUNN, 166

$7480 \mathrm{X}=\mathrm{USR}(0)$

7490 PARMOFFSET $=$ PEEK(PCAFUNN+2)*256 +PEEK(PCAFUNN+1)

7500 PARMSEG=PEEK(PCAFUNN+4) 256 + PEEK(PCAFUNN+3)

7510 DEF SEG=PARMSEG

7520 NET0 $=$ PEEK(PARMOFFSET)

7530 NET $]=($ PEEK $($ PARMOFFSET +1$)) * 256$ 
7540 NET2=(PEEK(PARMOFFSET+2))"65536!

7550 NET $3=($ PEEK(PARMOFFSET +3$))^{*} 16772216 \#$

7560 TOTALNET $=$ NET $0+N E T 1+N E T 2+$ NET 3

7570 REM

7580 REM

$7590 \mathrm{~F}=167$

7600 GOSUB 5900

7610 IF VALUE $0>0$ THEN TOTALNET $=0$

7620 RETURN

7630 REM

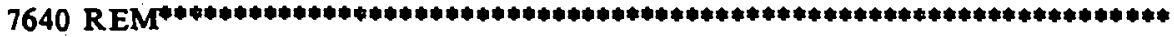

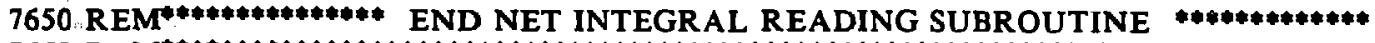

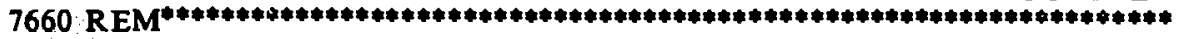

7670 REM

7680 REM

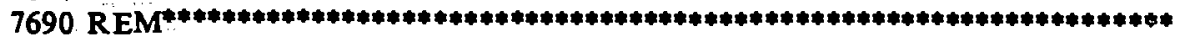

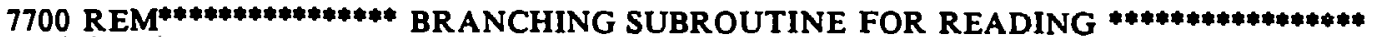

7710 REM

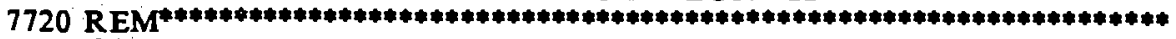

7730 REM

7740 REM

$7750 \mathrm{~F}=155$

7760 GOSUB 6140

$7770 \mathrm{~F}=34$

7780 GOSUB 6430

7790 GOSUB 7340

7800 REM

7810 REM

7820 REM

7830 RETURN

7840 BYTE $1=$ GOTO.BA.1 -256

7850 BYTE2 $=1$

7860 BYTE3 $=0$

7870 RETURN

7880 BYTE $I=$ GOTO.BA. 1

7890 B YTE2 $=0$

7900 BYTE $3=0$

7910 RETURN

7920 BYTE $1=255$

7930 BYTE2 $=0$

7940 BYTE3 $=0$

7950 RETURN

7960 REM

7970 BYTE $1=$ GOTO.BA.2 -1024

798ก BYTE2 $=4$

795. BYTE3 $=0$

8000 RETURN

8010 REM

8020 BYTE $1=$ GOTO.BA. 2 - 1280

8030 BYTE2 $=5$

8040 BYTE3=0

8050 RETURN

8060 REM

8070 BYTEl $=$ GOTO.BA.2-1536

8080 BYTE2 66

8090 BYTE3 $=0$ 
PROGRESS continued

8100 RETURN

8110 RLM

8120 K.EM

BREAK INTO BYTE-SIZE PIECES.

8130 REM

8140 BYTE $1=$ CALCAMCENT:BYTE2 $=0: B Y$ TE $3=0$

8150 RETURN

8160 BYTE $1=0: B Y T E 2=1: B Y T E 3=0$

8170 RETURN

8180 BYTE $1=$ CALCAMCENT $-256:$ BYTE $2=1: B Y T E 3=0$

8190 RETURN

8200 BYTE $1=$ CALCPUCENT $-256:$ BYTE $2=1:$ BYTE $3=0$

8210 RETURN

8220 BYTE $1=0:$ BYTE $2=2:$ BYTE $3=0$

$\$ 230$ RETURN

8240 BYTE $1=$ CALCPUCENT $-512:$ BYTE $2=2:$ BYTE $3=0$

8250 RETURN

8260 BYTE $1=$ CALCUCENT-512:BYTE2=2:BYTE $3=0$

8270 RETURN

8280 BYTE $1=0:$ BYTE $2=3:$ BYTE $3=0$

8290 RETURN

8300 BYTE $1=$ CALCUCENT $-768:$ BYTE2 $=3:$ BYTE $3=0$

8310 RETURN

8320 BYTE $1=$ CALCPU2CENT $-1536:$ BYTE $2=6:$ BYTE $3=0$

8330 RETURN

8340 BYTE $1=0:$ BYTE $2=7:$ BYTE $3=0$

8350 RETURN

8360 BYTE 1 =CALCPU2CENT-1792:BYTE2=7:BYTE3=0

8370 RETURN

8380 REM

8390 REM

8400 REM

INTERRUPT LOOF' AND MENU.

8410 CLS

8420 SCREEN $0,0,0$

8430 COLOR 13:LOCATE 3,23:PRINT"P":COLOR 11:LOCATE 3,24:PRINT" I ut o n i u m $^{n}$ 8440 COLOR 13:LOCATE 4,23:PRINT"R ${ }^{n}:$ COLOR 11:LOCATE 4,24:PRINT" e c o v e r $y^{n}$ 8450 COLOR 13:LOCATE 5,23:PRINT"O" ${ }^{n}$ :COLOR 11:LOCATE 5,24:PRINT" p e r a $t$ i o n s 8460 COLOR 13:LOCATE 6,23:PRINT"G":COLOR 11:LOCATE 6,24:PRINT" a m m a" 8470 COLOR 13:LOCATE 7,23:PRINT"R":COLOR 11:LOCATE 7,24:PRINT" a $y^{\prime \prime}$ 8480 COLOR 13:LOCATE 8,23:PRINT"E":COLOR 11:LOCATE 8,24:PRINT" n e r g y" $^{n}$ 8490 COLOR 13:LOCATE 9,23:PRINT"S":COLOR 11:LOCATE 9,24:PRINT" p e c t r o s c o p y" 8500 COLOR 13:LOCATE 10,23:PRINT"S":COL.OR 11:LOCATE 10,24:PRINT" y s t e m" 8510 COLOR 14:LOCATE 12,23:PRINT"Nuclear Materials Process Technology Group MST-12" 8520 LOCATE 13,23:PRINT"Research, Development and Demonstration" 8530 COLOR 10:LOCATE 17,23:PRINT"(1) RESUME CURRENT PROCESS MEASUREMENT" 8540 COLOR 10:LOCATE 18,23:PRINT ${ }^{n}$ (2) START NEW PROCESS MEASUREMENT ${ }^{n}$ 8550 COLOR 10:LOCATE 19,23:PRINT"(3) QUIT AND RETURN TO DOS" 8560 COLOR 11:LOCATE 21,23:INPUT"ENTER OPTION:",NEXT.OPTION 8570 ON NEXT.OPTION GOTO $1380,330,8590$ 8580 IF NEXT.OPTION $>3$ OR NEXT.OPTION $<1$ THEN 8620 8590 CLS

8600 LOCATE 10,23:COLOR 11:PRINT ${ }^{n}$ TYPE SYSTEM TO RETURN TO DOS 8610 END

8620 SOUND 500,5:LOCATE 22,23:PRINT"INCORRECT OPTION. PLEASE RE-ENTER RESPONSE" 8630 GOTO 8530 